\title{
Synergistic Radioprotection by Gamma-Tocotrienol and Pentoxifylline: Role of cAMP Signaling
}

\author{
Shilpa Kulkarni, ${ }^{1}$ Kushal Chakraborty, ${ }^{1}$ K. Sree Kumar, ${ }^{1}$ Tzu-Cheg Kao, ${ }^{1}$ \\ Martin Hauer-Jensen, ${ }^{2}$ and Sanchita P. Ghosh ${ }^{1}$ \\ ${ }^{1}$ Armed Forces Radiobiology Research Institute, Uniformed Services University of the Health Sciences, \\ Scientific Research Department, 8901 Wisconsin Avenue, Bethesda, MD 20889, USA \\ ${ }^{2}$ University of Arkansas for Medical Sciences and Central Arkansas Veterans Healthcare System, Little Rock, AR 72205, USA
}

Correspondence should be addressed to Shilpa Kulkarni; shilpa.kulkarni.ctr@usuhs.edu

Received 30 April 2013; Accepted 30 May 2013

Academic Editors: M. G. Andreassi and B. Puri

Copyright (c) 2013 Shilpa Kulkarni et al. This is an open access article distributed under the Creative Commons Attribution License, which permits unrestricted use, distribution, and reproduction in any medium, provided the original work is properly cited.

\begin{abstract}
Purpose. This study was designed to determine the efficacy and mechanisms of radioprotection by the combination of gammatocotrienol (GT3) and pentoxifylline (PTX) against acute radiation injury. Materials and Methods. Post-irradiation survival was monitored to determine the most efficacious dose and time of administration of PTX. Dose reduction factor (DRF) was calculated to compare the radioprotective efficacy of the combination. To determine the mechanism of synergistic radioprotection by the combination, mevalonate or calmodulin were coadministered with the GT3-PTX combination. Mevalonate was used to reverse the inhibitory effect of GT3 on 3-hydroxy-3-methyl-glutaryl-CoA reductase (HMGCR), and calmodulin was used to reverse the inhibition of phosphodiesterase (PDE) by PTX. Results. The combination was most effective when $200 \mathrm{mg} / \mathrm{kg}$ of PTX was administered $15 \mathrm{~min}$ before irradiation along with $200 \mathrm{mg} / \mathrm{kg}$ of GT3 $(-24 \mathrm{~h})$ and resulted in a DRF of 1.5. White blood cells and neutrophil counts showed accelerated recovery in GT3-PTX-treated groups compared to GT3. Mevalonate had no effect on the radioprotection of GT3-PTX; calmodulin abrogated the synergistic radioprotection by GT3-PTX. Conclusion. The mechanism of radioprotection by GT3-PTX may involve PDE inhibition.
\end{abstract}

\section{Introduction}

Exposure to lethal dose of ionizing radiation can lead to acute radiation syndrome (ARS), which is a combination of bone marrow, gastrointestinal, and cardiovascular-neuronal subsyndromes. These subsyndromes occur within hours to days based on the radiosensitivity of the tissue and the dose absorbed, and can be potentially life threatening [1]. Due to increased threat of nuclear fallout from terrorist activities and accidents at the nuclear power plants, major efforts are being invested in the development of radiation countermeasures to protect first responder military personnel and civilians [2]. Exposure to ionizing radiation is also a major concern in cancer patients undergoing radiation therapy [3]. However, no drug has been approved by Food and Drug Administration (FDA) to be used in humans against ARS.

Radiation-induced toxicity in various tissues is a manifestation of free radical generation, oxidative stress, DNA damage [4], inflammation, [5], and apoptotic signaling [6]. These signaling pathways are known to have deleterious effects in various diseases such as hypertension, diabetes, and cancer progression [5, 7]; therefore agents that have beneficial roles in modulating such signaling pathways may play important role in alleviating radiation-induced injury [8]. Various compounds such as antioxidants, thiols, antiapoptotic molecules, cytokine mimetic, and growth factors have been tested against acute radiation injury $[2,9,10]$. To determine the radioprotective efficacy of a countermeasure over a range of radiation doses, dose reduction factor (DRF) value is used. DRF is a ratio of $\mathrm{LD}_{50 / 30}$-drug over $\mathrm{LD}_{50 / 30}$-vehicle and is often used as a critical criterion used to compare efficacy of different radiation countermeasures in vivo. Several radiation countermeasure candidates with a DRF of 1.12 or more are being investigated for their potential use against acute radiation syndrome [11]. High DRF value is essential since 
it leads to protection from very high radiation doses. Our previous work on gamma-tocotrienol (GT3) [12] has shown that prophylactic treatment with GT3 $24 \mathrm{~h}$ prior to irradiation protects mice from radiation injury with a DRF of 1.29. Radioprotection by GT3 is associated with reduction of radiation-induced DNA damage [13] and inhibition of HMGCR-mediated-nitrosative stress [14]. GT3 is also shown to increase serum interleukin-6 (IL-6) and G-CSF levels; these cytokines are known to stimulate hematopoiesis. Induction of these cytokines may contribute to radioprotective action of GT3 [15]. In an attempt to enhance the radioprotective efficacy of GT3, we tested the effect of PTX, a methyl derivative of xanthine, in combination with GT3. PTX is an FDA-approved non-specific PDE inhibitor used for intermittent claudication [16, 17]. PTX has been used alone and in combination with vitamin $\mathrm{E}$ (alpha-tocopherol) in preclinical and clinical studies to reduce long-term effects of radiation such as fibrosis [18-20]. Beneficial effects of PTX are contributed to its ability to inhibit proinflammatory cytokine signaling such as tumor necrosis factor-alpha (TNF- $\alpha$ ) accumulation [21]. According to these studies, there was significant reduction in TNF- $\alpha$ in presence of PTX in early (2 weeks) as well as late (24 weeks) phase of radiation injury. It was recently shown that combining PTX with GT3 increased the radioprotective efficacy of GT3 in protecting mice from acute radiation injury [22]. These studies indicated that even though PTX increased the radioprotection in mice treated with GT3, its mechanism of protection was independent of endothelial nitric oxide synthase (eNOS). PTX is shown to increase nitric oxide production [23] by increasing cAMP levels. Also the effects of PTX on radiation-induced TNF- $\alpha$ levels and cAMP signaling were not evaluated. Current studies were conducted to systematically determine (a) the most efficacious time and dose of administration of PTX, (b) the DRF of the combination, and (c) the mechanisms of synergistic radioprotection by the combination. We conducted 30day survival study to determine the most efficacious dose and time of administration of PTX. We measured the percent survival over a wide range of radiation doses to calculate the DRF of the combination. We also tested radioprotective efficacy of PTX alone. We monitored peripheral blood counts to determine the effect of GT3 and PTX on the hematopoietic system. To decipher the mechanism of synergy between GT3 and PTX, we used mevalonate to reverse the effect of HMGCR inhibition by GT3 and calmodulin to reverse phosphodiesterase inhibition, and calcium and cAMP signaling [24, 25] such as PTX. Our results indicate that the increase in the radioprotective efficacy of GT3 by combining it with PTX was due to PDE inhibition, an effect that was reversed by calmodulin administration.

We also measured lipid hydroperoxide formation (malondialdehyde) in liver microsomes to determine the effect of PTX on the ability of GT3 to inhibit lipid peroxidation. Our results indicate that increase in the radioprotective efficacy of GT3 by combining it with PTX was due to an increase in cAMP and calcium signaling, an effect that was reversed by calmodulin administration.

\section{Materials and Methods}

2.1. Animals. Male CD2F1 mice (6-8 weeks old) purchased from Harlan Laboratories (Indianapolis, IN) were housed (eight per cage) at the Armed Forces Radiobiology Research Institute (AFRRI) in an air-conditioned facility accredited by the Association for Assessment and Accreditation of Laboratory Animal Care, International. Mice were maintained in air-conditioned rooms at a temperature of $21 \pm 2^{\circ} \mathrm{C}$ with a relative humidity of $50 \pm 10 \%$ and $10-15 \mathrm{~h}$ cycles of fresh air. The mice were quarantined for 2 weeks on arrival from the vendor. Microbiology, serology, and histopathology examination of representative samples ensured absence of Pseudomonas aeruginosa and common murine diseases. Mice were provided ad libitum a certified rodent diet (Harlan Teklad Rodent Diet no. 8604 (w), Madison, WI) and water acidified with $\mathrm{HCl}$ ( $\mathrm{pH} 2.5-3.0)$. All mice were kept in rooms with a $12 \mathrm{~h} \mathrm{light/dark}$ cycle with lights on from 0600 to $1800 \mathrm{~h}$. All animal procedures were performed in accordance with a protocol approved by the AFRRI's Institute of Animal Care and Use Committee (IACUC). Research was conducted according to the Guide for the Care and Use of Laboratory Animals, prepared by the Institute of Laboratory Animal Resources, National Research Council, and U.S. National Academy of Sciences.

2.2. Irradiation. Total-body irradiation (TBI) of unanesthetized mice was performed bilaterally in well-ventilated Plexiglas boxes (partitioned for 8 mice per box) in the AFRRI ${ }^{60} \mathrm{Co}$-radiation facility at a dose rate of $0.6 \mathrm{~Gy} / \mathrm{min}$ as described elsewhere [13]. ESR (electron spin resonance) dosimetry system (American Society for Testing and Material Standard E 1607) was used to measure dose rates (to water) in the cores of acrylic mouse phantoms. Phantoms were 3 inches long and 1 inch in diameter and were located in all other compartment of the exposure rack. The ESR signals were measured with a calibration curve based on standard calibration dosimeters provided by the National Institute of Standard and Technology (NIST). The accuracy of the calibration curve was verified by intercomparison with the National Physical Laboratory (NPL), United Kingdom. The only corrections applied to the dose rates in phantoms were for the decay of cobalt- 60 source and for a small difference in mass energy-absorption coefficients for water and soft tissue. The radiation field was uniform within $\pm 2 \%$. Radiation doses for hematological studies were chosen based on our previous studies [13] conducted with the same strain of mice to ensure the availability of live animals to serve as irradiated controls for the entire experimental period.

Radiation doses for hematological studies were chosen based on our previous studies conducted with the same strain of mice to ensure the availability of live animals to serve as irradiated controls for the entire experimental period.

2.3. Drug Formulation and Administration. GT3 was purchased as a formulation in 5\% Tween 80 in saline from Yasoo Health Inc. (Johnson City, TN). Vehicle control formulation containing an equivalent amount of olive oil in 5\% Tween 80 was also purchased from Yasoo Health Inc. The final GT3 
concentrations were adjusted to deliver $200 \mathrm{mg} / \mathrm{kg}$ of animal body weight in $0.1 \mathrm{~mL}$ formulation per animal. Control mice received $0.1 \mathrm{~mL}$ of vehicle. GT3 or vehicle were administered subcutaneously (SC) and aseptically (rubbing alcohol) at the nape of the neck with a 23 -gauge needle, $24 \mathrm{~h}$ prior to irradiation. There were no local reactions observed at the site of injection. PTX, calmodulin, and mevalonate were purchased from Sigma-Aldrich (St. Louis, MO) and were formulated in saline solution to deliver $0.1 \mathrm{~mL} \mathrm{SC}$ at the nape of the neck. Control mice received $0.1 \mathrm{~mL}$ of saline or $5 \%$ Tween 80 formulation (GT3 vehicle).

2.4. PTX, Mevalonate, and Calmodulin Dose and Time of Administration. Previous studies have shown that the optimum dose of GT3 was $200 \mathrm{mg} / \mathrm{kg}$ [12]. In order to determine the dose and time of administration of PTX, various treatment groups of 16 mice each were given $200 \mathrm{mg} / \mathrm{kg}$ of GT3 24 hour before, and 100 or $200 \mathrm{mg} / \mathrm{kg}$ of PTX 60,30, or $15 \mathrm{~min}$ utes before $11.5 \mathrm{~Gy}$ total body irradiation (TBI). We also monitored 30-day survival in mice administered with PTX alone $(200 \mathrm{mg} / \mathrm{kg},-30 \mathrm{~min})$. Mevalonate $(30 \mathrm{mg} / \mathrm{kg}$ ) was coadministered with GT3 $24 \mathrm{~h}$ prior to radiation. Calmodulin was coadministered with PTX $15 \mathrm{~min}$ prior to radiation. There were no reports on maximum tolerated doses (MTD) of calmodulin in mice; therefore, we conducted dose escalation toxicity studies up to 30 days. Mice were injected with 2000, 5000,10000 , and 20000 units of calmodulin in saline. They were monitored daily, and weighed every other day. No toxicity was observed in all the treatment groups. 5000 unit/mouse of calmodulin was used for survival studies. Calmodulin in saline was injected along with PTX 15 min before irradiation. After irradiation, mice were returned to their cages with free access to food and water and monitored for 30 days for weight loss and survival.

2.5. Determination of Dose Reduction Factor (DRF). DRF studies were performed as described elsewhere [12] using optimum dose of GT3 (200 mg/kg, $-24 \mathrm{~h})$. Based on the dose and time optimization studies, the following four treatment groups were used for calculation of DRF. (a) Vehicle $(-24 \mathrm{~h})$, (b) PTX (-15 min, $200 \mathrm{mg} / \mathrm{kg})$, (c) GT3 (200 mg/kg, $-24 \mathrm{~h}$ ), and (d) GT3 $(200 \mathrm{mg} / \mathrm{kg},-24 \mathrm{~h})$ plus PTX $(200 \mathrm{mg} / \mathrm{kg}$, $-15 \mathrm{~min}$ ) with 16 mice in each group. The vehicle-injected and PTX-injected groups were irradiated at 7.5, 8.0, 8.5, 9.0, 9.5, and 10.0 Gy TBI; GT3 and GT3-PTX-injected groups were irradiated at 10.5, 11.0, 11.5, 12.0, 12.5, and 13.0 Gy TBI. The range of radiation doses for vehicle or GT3-treated groups were selected based on previous observations so that the lowest radiation dose would result in $100 \%$ survival and the highest dose would result in $100 \%$ lethality. Survival was monitored for 30 days and $\mathrm{LD}_{50 / 30}$ doses for all three groups of mice were calculated using probit analysis. The DRF was calculated as the ratio of the $\mathrm{LD}_{50 / 30}$ of GT3-PTX-treated mice to the $\mathrm{LD}_{50 / 30}$ of vehicle-treated mice with $95 \%$ confidence interval.

2.6. Peripheral Blood Cell Counts. Mice were given one of the following treatments: (a) vehicle $(-24 \mathrm{~h}),(\mathrm{b})$ PTX $(100 \mathrm{mg} / \mathrm{kg},-15 \mathrm{~min}),(\mathrm{c})$ GT3 $(-24 \mathrm{~h})$, or (d) GT3 (-24 h) and PTX $(100 \mathrm{mg} / \mathrm{kg},-15 \mathrm{~min})$ and irradiated at $8 \mathrm{~Gy}$ at a dose rate of $0.6 \mathrm{~Gy} / \mathrm{min}$. This radiation dose was chosen so the vehicle-treated group would survive for the duration of the experiment (up to 60 days after irradiation). Corresponding sham-irradiated treatment groups were also used for control. Eight mice were used for each treatment group and blood was collected at $0,1,4,7,17$, and 30 days after irradiation. Blood was collected $(0.6 \mathrm{~mL})$ from the posterior vena cava with a 23-gauge heparinized needle from mice after anesthetizing mice with isoflurane (Hospira Inc., Lake Forest, IL, USA). Blood was transferred immediately into ethylenediamine tetra-acetic acid (Sigma) containing blood collection tubes and mixed gently on a rotary shaker until analysis. Total white blood cells (WBC), absolute neutrophil counts (ANC), monocytes (MONO), lymphocytes (LYMP), platelets (PLT), and reticulocytes (RETIC) were measured using an Advia 120 cell counter (Bayer Corporation, Tarrytown, NY).

2.7. Bone Marrow Collection. For each treatment group, 6 mice were humanely euthanized at time points 0,4 , and 7 days post-irradiation. Femurs from 2 mice were pooled for each sample. Femurs were flushed with sterile phosphate buffer saline (PBS) containing $2 \%$ fetal bovine serum (FBS) (ATCC, Manassas, VA) using a $23 \mathrm{G}$ needle. The cells were separated using a $18 \mathrm{G}$ needle. Cell suspensions were filtered through a strainer and centrifuged at $400 \mathrm{~g}$ for 5 minutes at $4^{\circ} \mathrm{C}$. Nucleated cells were counted using Beckman Coulter Counter (Beckman Coulter, Indianapolis, IN).

2.8. Estimation of Lipid Peroxides in Stimulated Liver Microsomes. Lipid peroxidation in stimulated liver microsomes was measured as thiobarbituric acid reactive species (TBARS). All chemicals were purchased from Sigma Aldrich. Liver microsomes were incubated with millimolar amounts of ferrous ammonium sulfate and $\mathrm{NADPH}$ in presence of GT3 and PTX alone and in combination at various concentrations for 15 minutes at room temperature. 10\% trichloro acetic acid (TCA) was added to each sample to precipitate lipids and proteins and left on ice for 30 minutes. Samples were centrifuged for 15 minutes at $2000 \mathrm{~g}$ at 4 degrees. Supernatant was transferred to a glass tube. Finally $200 \mu \mathrm{L}$ of $0.67 \%$ thiobarbituric acids (TBA) was added to the supernatant and incubated in boiling water (over 90 degrees) for 10 minutes. The solutions were cooled to room temperature. Absorbance was recorded to measure amounts of TBARS at $535 \mathrm{~nm}$. Known concentrations of TBA were used to generate a standard curve. Each data point was measured in triplicate with each experiment repeated twice. Percent inhibition was calculated based on TBARS species produced by NADPH in microsomes.

2.9. Serum Cytokine Analysis. Blood was collected (0.6 to $1.0 \mathrm{~mL}$ ) from posterior vena cava with a 23-gauge heparinized needle from mice after deep anesthesia with isoflurane (Hospira Inc., Lake Forest, IL, USA). It was transferred immediately into serum separator tubes and allowed to clot for $30 \mathrm{~min}$ at room temperature. After centrifugation at $2000 \mathrm{~g}$ for $10 \mathrm{~min}$, serum was transferred to a fresh micro-centrifuge tube and stored at -80 degrees. Serum samples were thawed 


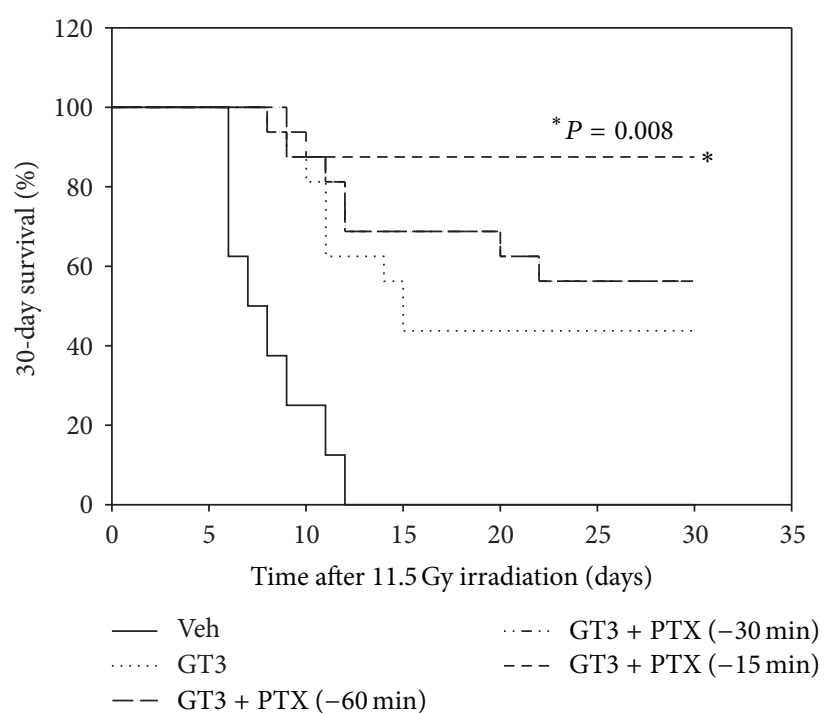

(a)

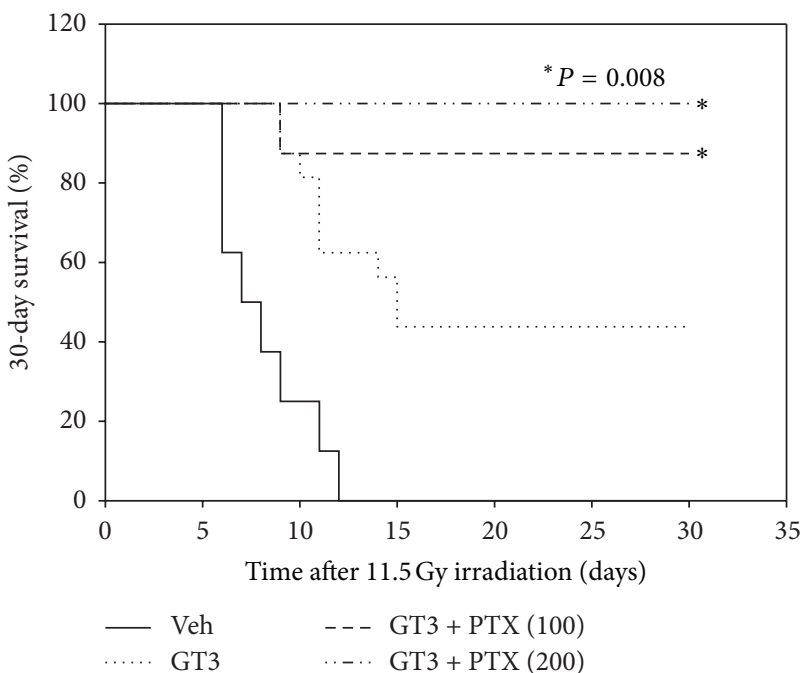

(b)

FIGURE 1: GT3-PTX combination increased the radioprotective efficacy of GT3 at 11.5 Gy. Postirradiation survival studies were conducted on mice $(n=16)$ treated with GT3 or PTX or a combination of GT3 and PTX. (a) shows time optimization studies on GT3 (200 mg/kg) and PTX $(100 \mathrm{mg} / \mathrm{kg})$ combination. GT3-PTX $(-15 \mathrm{~min})$ combination provided significantly greater protection than GT3 $\left({ }^{*} P=0.008\right)$. All groups treated with GT3 alone or in combination with PTX significantly improved the survival in mice compared to vehicle $(P=0.0004)$. $(\mathrm{b})$ shows that $100 \mathrm{mg} / \mathrm{kg}$ and $200 \mathrm{mg} / \mathrm{kg}$ of PTX significantly increased survival over GT3 alone $\left({ }^{*} \mathrm{P}=0.008\right)$. There was PTX-dose dependent increase in radioprotection but statistically it was not significant.

and processed using Bio-Rad manufacturer's protocol. Sandwich immunoassay protocol was used to measure several cytokines (23-plex-Bio Rad) using multiplex Luminex assay. Six mice were used for each data point. The samples were analyzed using Bio-Rad's Luminex 200 instrument.

2.10. Statistical Analysis. For the survival data, Fisher's exact test was used to compare \% survival at 30 days with Bonferroni adjustment. The Log-rank test was used to compare survival curves. Means and standard errors were reported for peripheral blood counts. Analysis of variance (ANOVA) was used to determine if there was a significant difference among different groups. For a given day, if there was a significant difference among the groups, a pair-wise comparison was done using the Tukey-Kramer method. The significance level was set at $5 \%$ for each test. All statistical tests were two-sided. Statistical software, PC SAS, was used for statistical analyses.

\section{Results}

3.1. Determination of the Most Effective Time and Dose of Administration of PTX for the Radioprotective Efficacy of the GT3-PTX Combination. Time and dose of administration of PTX were chosen based on the previous studies conducted on PTX [26]. To determine the most efficacious time of administration of PTX, $100 \mathrm{mg} / \mathrm{kg}$ of PTX was administered $60 \mathrm{~min}, 30 \mathrm{~min}$, or $15 \mathrm{~min}$ before irradiation. Percent survival (30-day) of mice treated with $200 \mathrm{mg} / \mathrm{kg}$ of GT3 (-24 h) and $100 \mathrm{mg} / \mathrm{kg}$ of PTX given at various times before $11.5 \mathrm{~Gy}$ irradiation is shown in Figure 1(a). The combination was most effective when PTX was given 15 min before TBI and least effective when PTX was administered 60 min before TBI. Thus administration of PTX closer to the time of irradiation was crucial for the radioprotective efficacy of the combination. Single injection of 100 or $200 \mathrm{mg} / \mathrm{kg}$ of PTX was administered to determine the most efficacious dose. Percent survival (30-day) of mice treated with $200 \mathrm{mg} / \mathrm{kg}$ of GT3 and two different doses of PTX before radiation (11.5 Gy TBI) is shown in Figure 1(b). There were no survivors in the vehicle-treated groups. $200 \mathrm{mg} / \mathrm{kg}$ and $100 \mathrm{mg} / \mathrm{kg}$ PTX in combination with GT3 resulted in $100 \%$ and $87.5 \%$ survival, respectively. Thus, the combination increased the postirradiation survival $(P=0.008)$ for both doses of PTX tested compared to the GT3 group alone. There was no significant difference between 100 and $200 \mathrm{mg} / \mathrm{kg}$ of PTX. Therefore, $200 \mathrm{mg} / \mathrm{kg}$ of PTX was used for survival studies, and $100 \mathrm{mg} / \mathrm{kg}$ of PTX was used for hematological studies.

3.2. Radioprotective Efficacy of PTX Alone. To determine whether increase in radioprotective efficacy by combining PTX with GT3 was an effect, we conducted 30-day postsurvival studies with PTX alone. PTX was administered $15 \mathrm{~min}$ before $8.5 \mathrm{~Gy} \mathrm{TBI}$, and postirradiation survival was monitored for 30 days. As shown in Figure 2, there was no significant increase in postirradiation survival with PTX alone compared to the vehicle. These studies indicate that PTX alone was a poor radiation countermeasure. Thus protective effect of GT3-PTX combination was not merely an additive effect of GT3 and PTX.

3.3. Determination of Dose Reduction Factor (DRF). We reported earlier that the DRF for $200 \mathrm{mg} / \mathrm{kg}$ GT3 was 1.29 


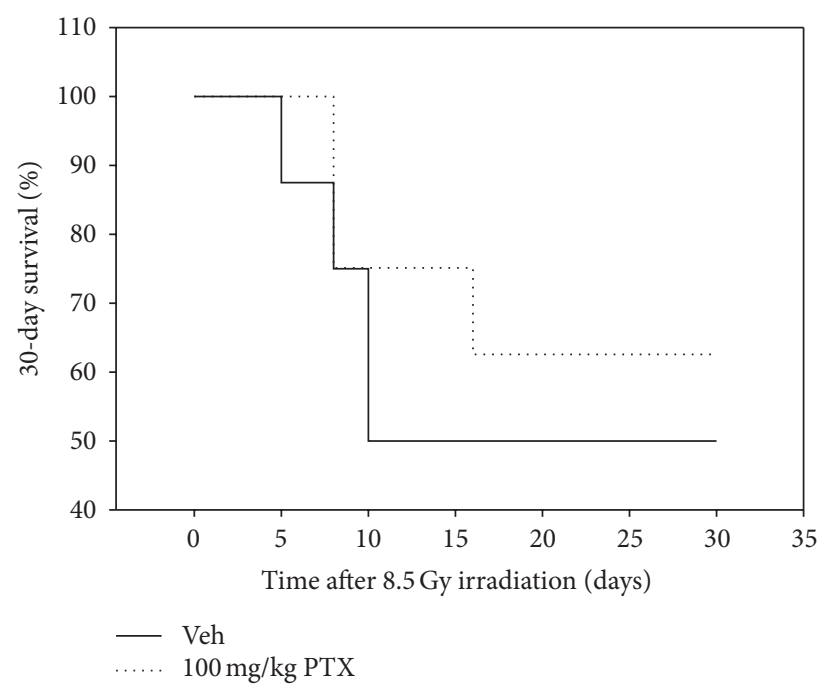

FIgURE 2: Effect of PTX alone on the postirradiation survival in mice Percent survival in mice $(n=16)$ treated with $200 \mathrm{mg} / \mathrm{kg}$ PTX or vehicle (saline) irradiated at $8.5 \mathrm{~Gy}$ TBI was followed for 30 days after irradiation. PTX did not increase postirradiation survival significantly, indicating that it is a poor radiation countermeasure when used alone.

[12]. In order to determine the radioprotective efficacy of GT3 combined with $200 \mathrm{mg} / \mathrm{kg}$ of PTX, DRF was calculated (Figure 3) for vehicle, GT3, and the GT3-PTX combination. There was no significant difference in the $\mathrm{LD}_{50 / 30}$ radiation doses between vehicle $(8.5 \mathrm{~Gy})$ and PTX $(9.1 \mathrm{~Gy}) . \mathrm{LD}_{50 / 30}$ doses were determined to be 11.01 (95\% CI) Gy for GT3 and 12.5 (95\% CI) Gy for the GT3-PTX combination. DRF of 1.5 (95\% CI 1.45-1.54, Figure 3) was obtained for the GT3-PTX combination, which was significantly higher than the DRF reported for GT3.

\subsection{Effect of the GT3-PTX Combination on Radiation-Induced} Cytopenia. Exposure to $8 \mathrm{~Gy}$ TBI resulted in rapid depletion of white blood cells (WBC), and absolute neutrophils (ANC) as observed in Figures 4(a) and 4(b), respectively. Vehicletreated and PTX-treated groups reached nadir at day 7. There was no difference in the declination or recovery profile between irradiated vehicle- and PTX-treated groups for WBC and ANC; on the other hand, GT3 and GT3-PTX treatment groups showed accelerated recovery in $\mathrm{WBC}$ and $\mathrm{ANC}$ at days 7 and 17. WBC and ANC in GT3-PTX-treated group were significantly greater $(P<0.04)$ than GT3-treated group on day 7 at day 30 all irradiated groups showed complete recovery in $\mathrm{WBC}$ and $\mathrm{ANC}$.

3.5. Effect of the GT3-PTX Combination on Bone Marrow Cells. Bone marrow leukocyte population was measured in femurs to determine the hematopoietic recovery in progenitors. As shown in Figure 5, irradiation resulted in depletion of bone marrow; however, GT3- and GT3-PTX-treated groups showed remarkable recovery at day 7 compared to vehicleand PTX-treated groups. More importantly, GT3-PTX group showed higher cellularity $(P=0.03)$ than GT3 alone group.

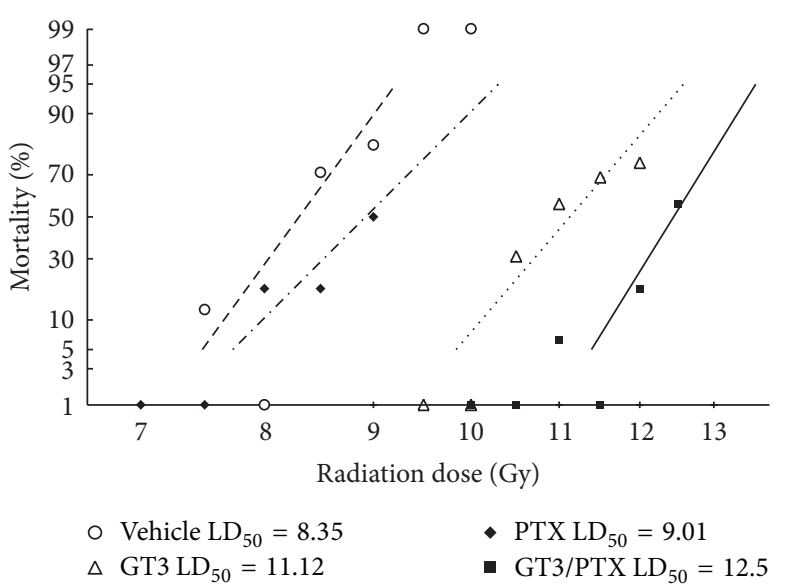

FIGURE 3: Determination of dose reduction factor for the GT3-PTX combination. Mice $(n=16)$ treated with one of the treatment groups (vehicle, $200 \mathrm{mg} / \mathrm{kg}$ of PTX, $200 \mathrm{mg} / \mathrm{kg}$ of GT3, and $200 \mathrm{mg} / \mathrm{kg}$ of GT3 plus $200 \mathrm{mg} / \mathrm{kg}$ of PTX) were exposed to a range of different radiation doses. The vehicle-injected and PTX-injected groups were irradiated at 7.5, 8.0, 8.5, 9.0, 9.5, and 10.0 Gy TBI; GT3 group was irradiated at $9.5,10.0,10.5,11.0,11.5$, and 12.0 Gy TBI. GT3-PTXinjected groups were irradiated at 10.0, 10.5, 11.0, 11.5, 12.0, and 12.5 Gy TBI. Postirradiation survival was used to generate probit curve. Dose required for $50 \%$ mortality at 30 days $\left(\mathrm{LD}_{50 / 30}\right)$ was calculated for each treatment group. Ratio of $\mathrm{LD}_{50 / 30}-\mathrm{drug} / \mathrm{LD}_{50 / 30^{-}}$ vehicle, also known as dose reduction factor (DRF), was calculated as an index of radioprotective efficacy over a range of radiation doses with $95 \%$ confidence interval.

Thus, increase in bone marrow cellularity was preceded with an equivalent recovery in peripheral blood cells.

3.6. Effect of GT3-PTX on Serum Cytokines and Chemokines. 23-plex mouse cytokine assay (Bioplex, BioRad, Hercules, CA) was conducted on serum samples from mice on days 0,1 and 2 after 8 Gy TBI. As indicated in Figure 6, granulocyte colony-stimulating factor (G-CSF), keratinocyte chemoattractant (KC), and interleukin-6 (IL-6) were upregulated and TNF- $\alpha$ was downregulated by GT3-PTX treatment. GT3 and GT3-PTX treatment upregulated IL-6 (3-fold) in the unirradiated groups, this effect disappeared in irradiated groups. GCSF was strongly stimulated in mice treated with GT3 and GT3-PTX compared to the vehicle group. G-CSF stimulation was observed in irradiated $(40,000 \mathrm{pg} / \mathrm{mL})$ as well as unirradiated $(50,000 \mathrm{pg} / \mathrm{mL})$ groups, and the levels remained significantly high on days 0,1 , and 2 postirradiation. PTX had no effect on G-CSF levels. IL-6 levels in GT3 and GT3-PTX groups were significantly higher $(90 \mathrm{pg} / \mathrm{mL}, P<0.05)$ than vehicle- or PTX-treated groups only on day 0 . One day after irradiation, IL-6 levels did not change significantly in irradiated groups. KC was upregulated 4-fold in mice treated with GT3 and GT3-PTX as compared to vehicle- and PTXtreated groups on days 0 and 1 after radiation. KC levels were not significantly different in irradiated groups. TNF- $\alpha$, a proapoptotic cytokine [27] increased almost 2-fold in all treatment groups 1 day after irradiation and continued to increase (5-fold) in vehicle- and PTX-treated groups 2 days 


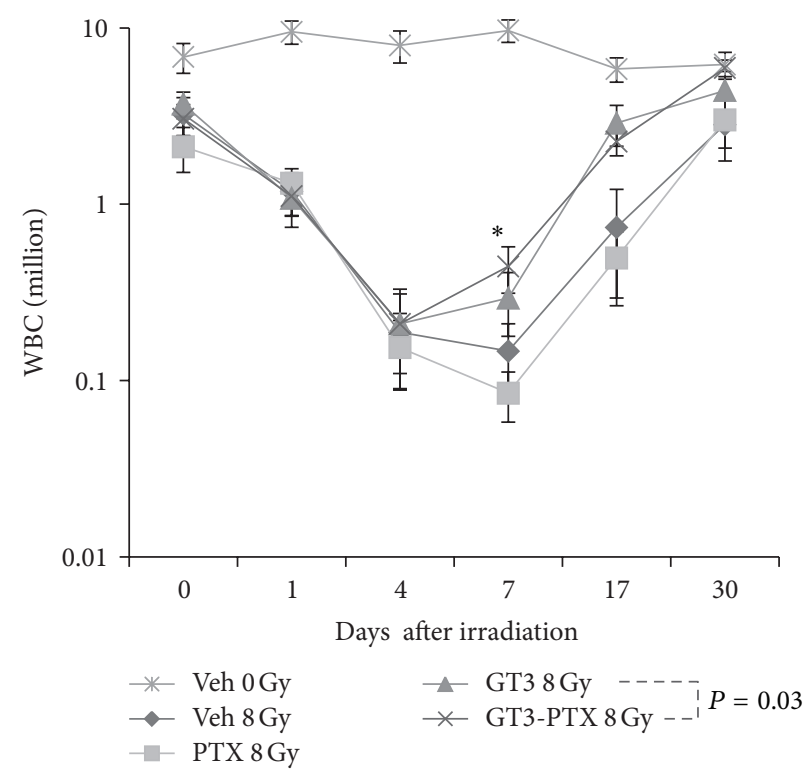

(a)

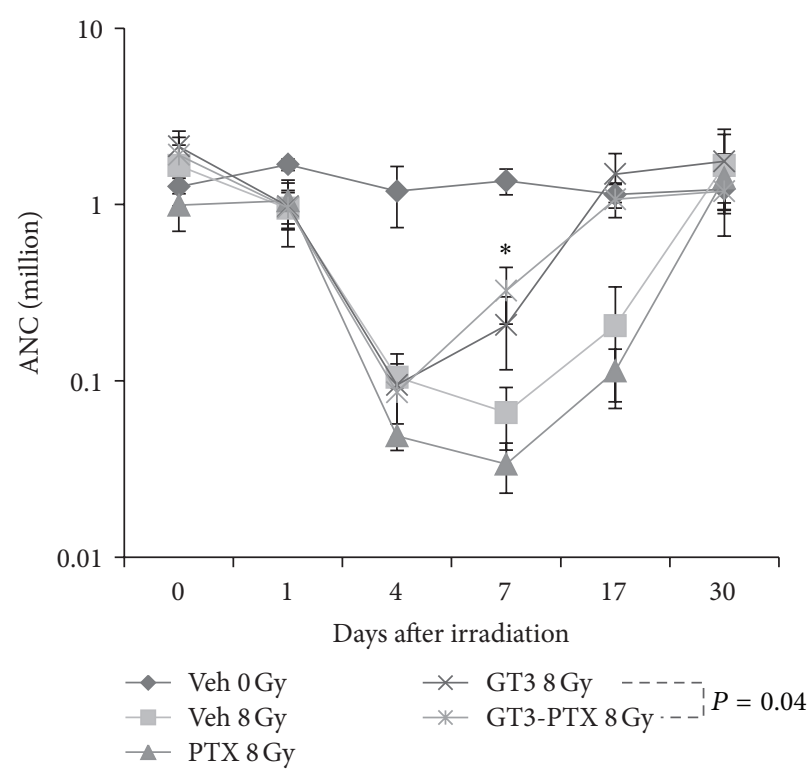

(b)

Figure 4: Effect of GT3-PTX combination on peripheral blood cells. Mice $(n=8)$ treated with various treatment groups (vehicle, $100 \mathrm{mg} / \mathrm{kg}$ PTX, $200 \mathrm{mg} / \mathrm{kg}$ GT3, $200 \mathrm{mg} / \mathrm{kg}$ GT3 plus $100 \mathrm{mg} / \mathrm{kg}$ PTX) were exposed to $8 \mathrm{~Gy}$ TBI. Corresponding unirradiated controls were also included in the experiment. (a) and (b) show WBC and ANC over a period of 30 days. GT3-PTX combination shows accelerated recovery in WBC $\left({ }^{*} P=0.03\right)$ and $\operatorname{ANC}\left({ }^{*} P=0.04\right)$ at day 7 . At day 30 , all irradiated groups reached the normal levels.

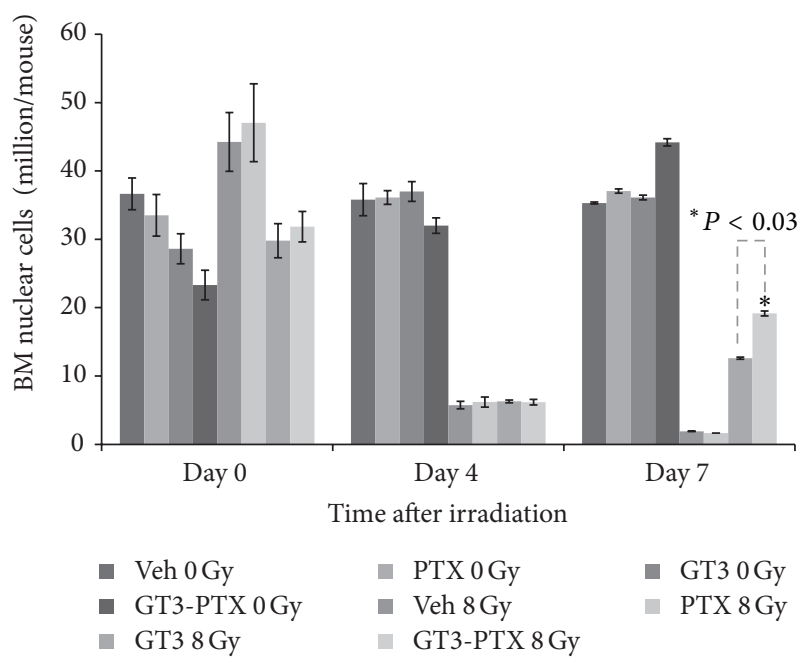

Figure 5: Effect of GT3-PTX on bone marrow cellularity. Bone marrow nucleated cells harvested from femurs $(n=6)$ at days 1 , 4 , and 7 after 8 Gy TBI from one of the following groups: vehicle, $100 \mathrm{mg} / \mathrm{kg}$ PTX, $200 \mathrm{mg} / \mathrm{kg}$ GT3, $200 \mathrm{mg} / \mathrm{kg}$ GT3 plus $100 \mathrm{mg} / \mathrm{kg}$ PTX. Corresponding unirradiated controls were also included in the experiment. GT3-PTX combination shows significantly higher bone marrow cellularity $\left({ }^{*} \mathrm{P}=0.03\right)$ compared to GT3 alone group at day 7 post-TBI.

after irradiation. GT3 treatment decreased radiation-induced TNF- $\alpha$ levels to some extent; combining GT3 with PTX decreased TNF- $\alpha$ levels even further $(P=0.04)$.

3.7. Effect of GT3-PTX Combination on Lipid Peroxidation. To determine whether PTX contributed to alleviating oxidative stress generated due to ionizing radiation, we used in vitro assay to measure lipid peroxidation in liver microsomes incubated with GT3 and PTX either alone or in combination. As shown in Figure 7, micromolar amount of GT3 $(4 \mu \mathrm{M})$ effectively inhibited lipid peroxidation by $50 \%(P=0.001)$, whereas as much as $50 \mathrm{mM}$ PTX did not inhibit lipid peroxidation. GT3-PTX combination also reduced lipid peroxidation by $50 \%$, which was similar to the inhibition obtained with GT3 alone. Thus PTX had no effect on antioxidant activity of GT3.

3.8. Effect of Mevalonate on Radioprotection by the GT3-PTX Combination. GT3 is shown to reduce vascular oxidative stress in irradiated mice through its anti3-HMGCR properties [14]. To determine the role of HMGCR inhibition in GT3-PTX synergistic protection, mice were cotreated with GT3-mevalonate and PTX prior to $12 \mathrm{~Gy}$ TBI. As shown in Figure 8(a), postirradiation survival in GT3-PTX (56\%) and GT3-PTX-mevalonate (62.5\%) groups was similar. Groups treated with the GT3-PTX and the GT3-PTXmevalonate combination showed significantly higher survival compared to GT3 (31.25\%) alone group. Thus mevalonate did not reverse the effect of GT3-PTX indicating that synergy between GT3 and PTX did not affect the mevalonate pathway.

3.9. Effect of Calmodulin on Radioprotection by the GT3PTX Combination. PTX is known to increase cAMP levels by inhibition of phosphodiesterases and modulating calcium-calmodulin signaling pathways $[28,29]$. To determine the effect of cAMP and calcium signaling on GT3PTX synergistic radioprotection, mice were treated with 


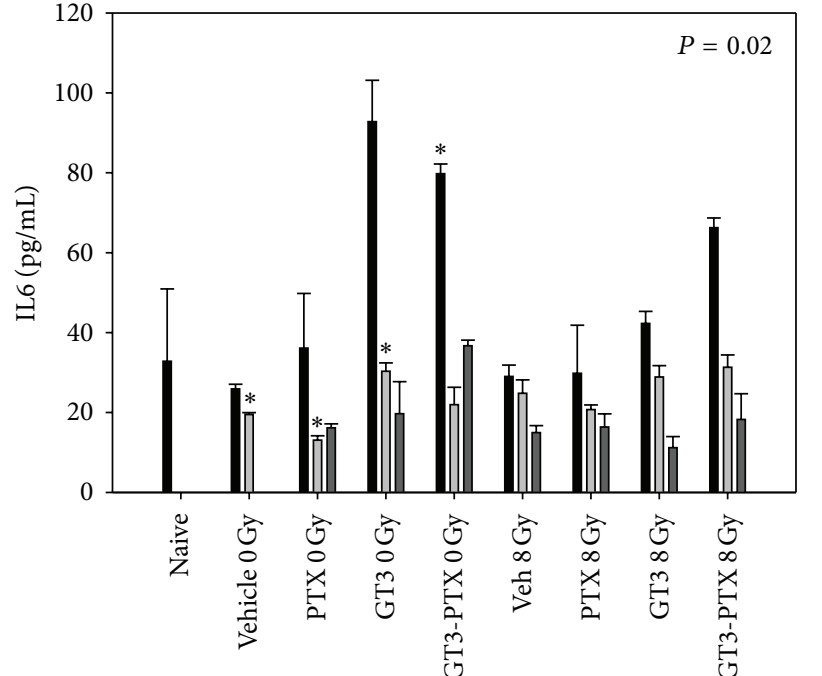

Time after irradiation (days)

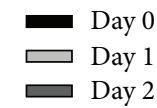

(a)

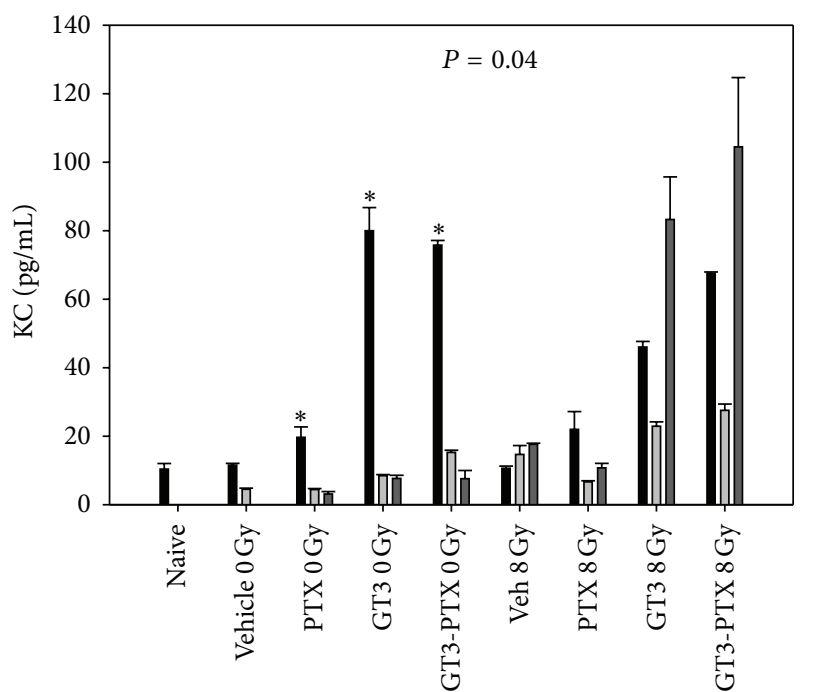

Time after irradiation (days)

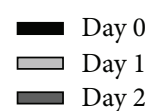

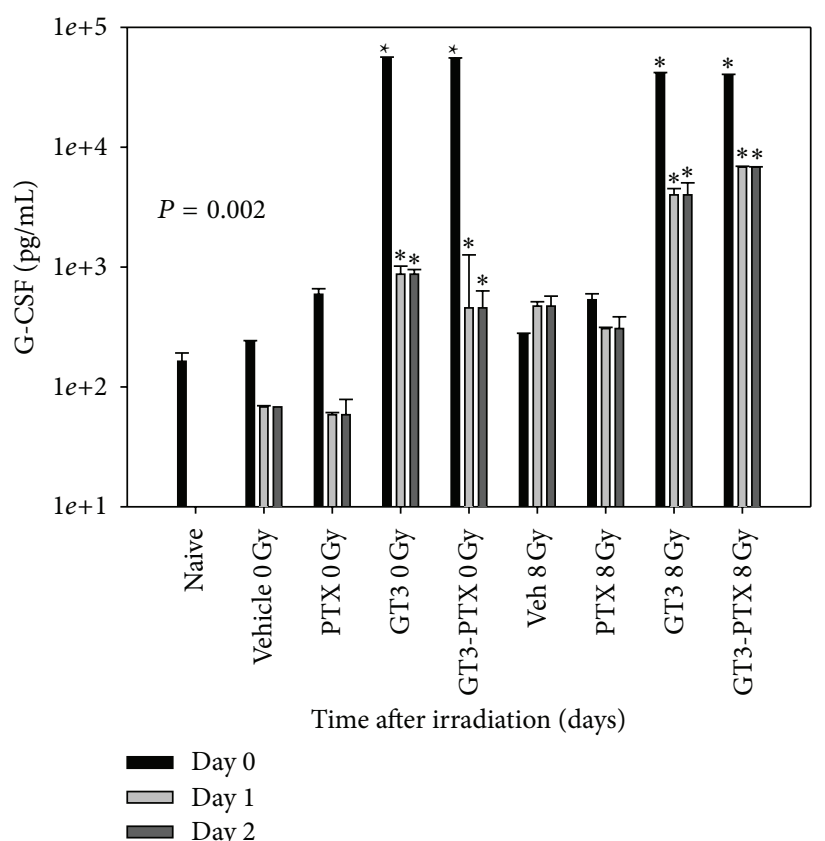

(b)

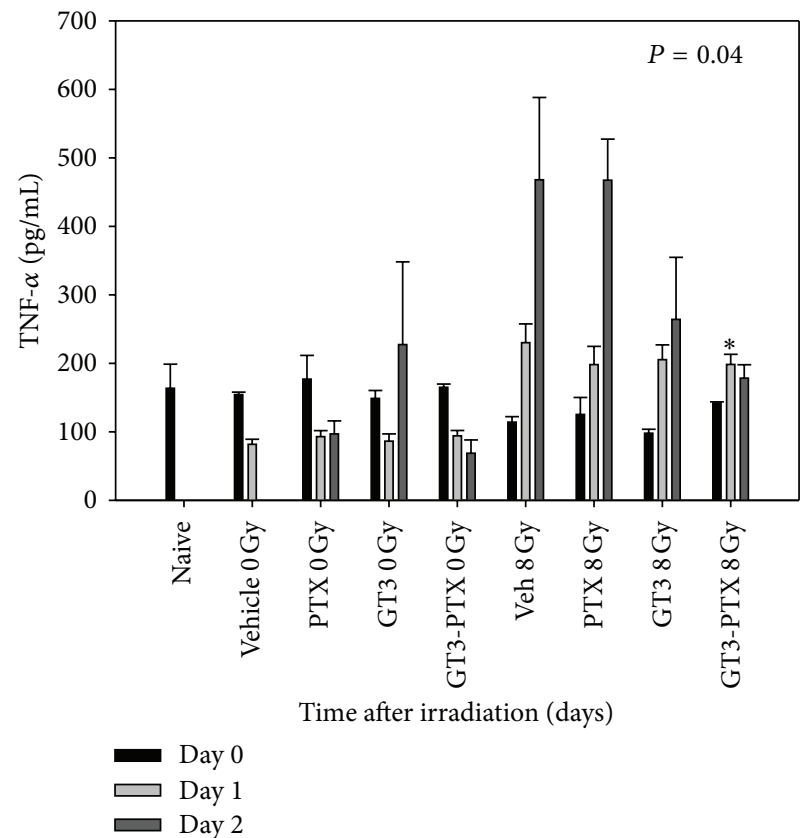

(d)

Figure 6: Effect of $200 \mathrm{mg} / \mathrm{kg}$ GT3 plus $100 \mathrm{mg} / \mathrm{kg}$ of PTX combination on serum cytokines. Among 21 cytokines analyzed in the serum samples, (a) interleukin 6 (IL-6), (b) granulocyte colony-stimulating factor (G-CSF), (c) keratinocyte chemoattractant (KC), and (d) tumor necrosis factor $\alpha$ (TNF- $\alpha$ ) levels were altered in GT3 and GT3-PTX-treated groups. High levels of G-CSF, IL-6, and KC were observed with GT3 and GT3-PTX treatment $\left({ }^{*} P<0.05\right)$. GT3-PTX combination synergistically decreased the levels of TNF- $\alpha$ by 3 -fold compared to vehicle $\left({ }^{*} P<0.04\right)$

GT3-PTX and GT3-PTX-calmodulin before 12 Gy TBI. Percent postirradiation survival was followed for 30 days and plotted in Figure 8(b). Survival in groups treated with GT3PTX $(62.5 \%)$ was significantly higher $(P=0.034)$ than groups treated with GT3-PTX-calmodulin (25\%). GT3-PTXcalmodulin group showed similar survival compared to GT3 alone group indicating that calmodulin was able to reverse the synergistic radioprotective effect of the GT3-PTX combination. Figure $8(\mathrm{c})$ is a representation of $\%$ survival at the end of 30 days postirradiation studies. GT3-PTX-calmodulin treatment show significantly lower survival compared to the GT3-PTX, and GT3-PTX-mevalonate combination. 


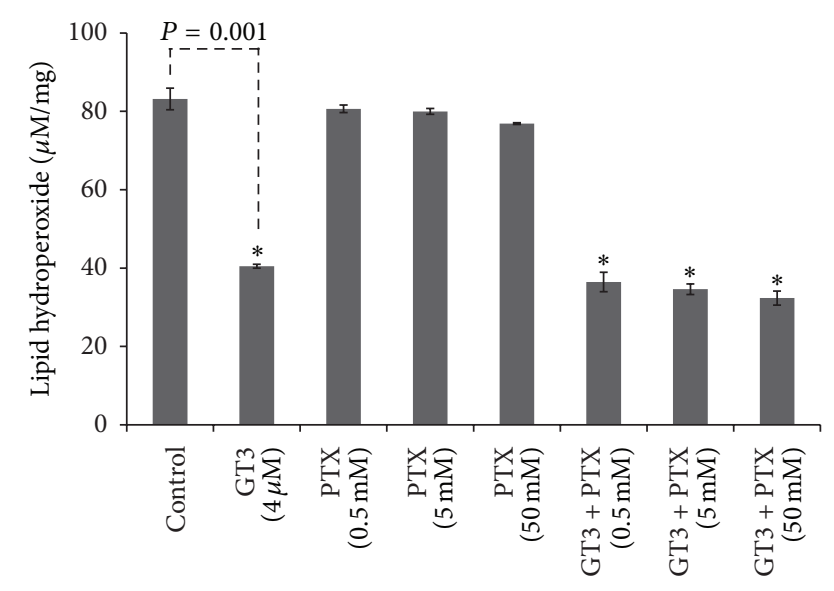

FIGURE 7: Effect of GT3-PTX combination on lipid peroxidation in liver microsomes. Lipid peroxidation was measured in millimolar amounts in the ferrous ammonium sulfate and NADPH stimulated liver microsomes incubated with various amounts of GT3 and PTX. Formation of lipid hydorperoxide, mainly malondialdehyde, was measured as a function of thiobarbituric acid reactive species per $23 \mathrm{mg}$ of protein from the microsomes. GT3 containing samples show dramatic reduction in lipid peroxidation $\left({ }^{*} P=0.001\right)$.

\section{Discussion}

GT3 has shown promising radioprotective efficacy in mouse model when used $24 \mathrm{~h}$ prior to total body irradiation [12]. The protective effect of GT3 in preventing DNA damage and protecting stem cells [13] can in part be attributed to its free radical scavenging properties. Recent report also suggests modulation of tetrahydrobiopterin a key component of HMGCR-nitric oxide synthase (NOS) signaling by GT3 [22]. PTX has been successfully used alone and in combination with vitamin E alpha-tocopherol (AT) $[18,30]$ to ameliorate radiation-induced late effects such as lung fibrosis. These results indicated that GT3 protected mice from acute injury, and PTX protected from radiation-induced late injuries when used alone or in combination with AT. We hypothesized that combining PTX with GT3 may result in protection against radiation-induced acute as well late effects. It was reported earlier that combining GT3 with PTX improves the efficacy of GT3 in protecting against acute radiation injury [22]. However, this effect was observed only in the hematopoietic tissue, and these studies were conducted with $400 \mathrm{mg} / \mathrm{kg}$ of GT3, a 2-fold higher dose of GT3. Present studies were conducted to determine the optimum time and dose of administration of PTX. Plethora of literature indicated that PTX reached optimum dose in the circulation minutes after administration [31]. The efficacy of the combination was very sensitive to time of administration of PTX. We also determined the dose reduction factor, an important index used to compare efficacy of a radiation countermeasure over a range of radiation doses. DRF is used to compare the efficacy of potential radiation countermeasures in animal models [11]. DRF for GT3-PTX combination was 1.5; whereas, for GT3 it was 1.3 [12]. Thus, combining PTX with GT3 increased the $\mathrm{LD}_{50 / 30}$ value from 11.2 to 12.5 , and $\mathrm{DRF}$ from 1.3 to 1.5 , which is a significant increase in the efficacy.

Peripheral blood counts from mice exposed to 8 Gy TBI did not show any protection by PTX $(100 \mathrm{mg} / \mathrm{kg})$ alone, PTX treatment prolonged ANC nadir at 8 Gy. GT3 and the GT3-PTX combination accelerated recovery of white blood cells, and neutrophils significantly over the vehicle control in irradiated mice. The GT3-PTX combination was more effective in the recovery of WBC and ANC compared to the GT3 treatment group indicating that the recovery from cytopenia in peripheral blood was preceded by increase in bone marrow cellularity. The GT3-PTX combination also repopulated bone marrow to a greater extent at day 7 compared to GT3 treatment group. Similar results were reported with higher doses of GT3 $(400 \mathrm{mg} / \mathrm{kg}$ instead of $200 \mathrm{mg} / \mathrm{kg}$ ) and PTX $(200 \mathrm{mg} / \mathrm{kg}$ instead of $100 \mathrm{mg} / \mathrm{kg}$ ) [22]. Cytokines induced in response to GT3 treatment such as G-CSF, IL-6, and KC are known to stimulate the hematopoietic system [32]. GCSF in particular and its related synthetic forms are used to protect against radiation-induced myelosuppression $[10,32$, 33]. Recent studies show that radioprotection by GT3 may involve G-CSF induction $[15,34]$. PTX had no beneficial effects on G-CSF, IL6 or KC. Only TNF- $\alpha$ was significantly reduced by GT3-PTX $(P=0.04)$. Ionizing radiation is known to induce TNF- $\alpha$ signaling, which has various pathological effects $[27,35]$. An inhibitory effect of GT3-PTX on TNF$\alpha$ may contribute to the increased overall protection from radiation injury.

To determine the underlying mechanism of this synergistic protection, we used (a) mevalonate to reverse GT3-mediated HMGCR inhibition, and (b) calmodulin to reverse PTXinduced cAMP signaling. GT3 along with delta-tocotrienol (DT3) are potent inhibitors of HMGCR, which is a rate limiting enzyme in cholesterol biosynthesis [36]. Anticancer properties of GT3 were recently shown to be mediated by its ability to inhibit the mevalonate pathway [37]. Therefore the effect of GT3-PTX on HMGCR inhibition was tested on postirradiation survival. Mice cotreated with mevalonate along with GT3-PTX combination were exposed to $12.0 \mathrm{~Gy}$ TBI, and postirradiation survival was monitored for 30 days. $\mathrm{LD}_{50 / 30}$ dose for the GT3-PTX combination (12 Gy) was chosen for these experiments based on the DRF studies. Survival data indicated that mevalonate did not reverse the GT3-PTX combination effects indicating that the synergistic protection offered by GT3-PTX was independent of the antiHMGCR property of GT3. Similar studies were conducted with calmodulin. Calmodulin is known to inhibit cAMP signaling $[24,38]$, and reverse the effect of PDE inhibitors such as PTX. We hypothesized that administration of calmodulin may potentially inhibit synergistic effect of GT3-PTX on cAMP signaling. Cotreatment of calmodulin indeed reversed the effect of the GT3-PTX synergistic radioprotection. The reversal of protection in mice in response to calmodulin indicates that CAMP induction in presence of PTX may contribute to the synergistic radioprotection by GT3-PTX. Thrombomodulin, a membrane glycoprotein in endothelial cells that activates protein $\mathrm{C}$ pathway, is known to protect endothelium from radiation injury [39]. It is also known to be up-regulated in response to increase in cAMP [40]. 


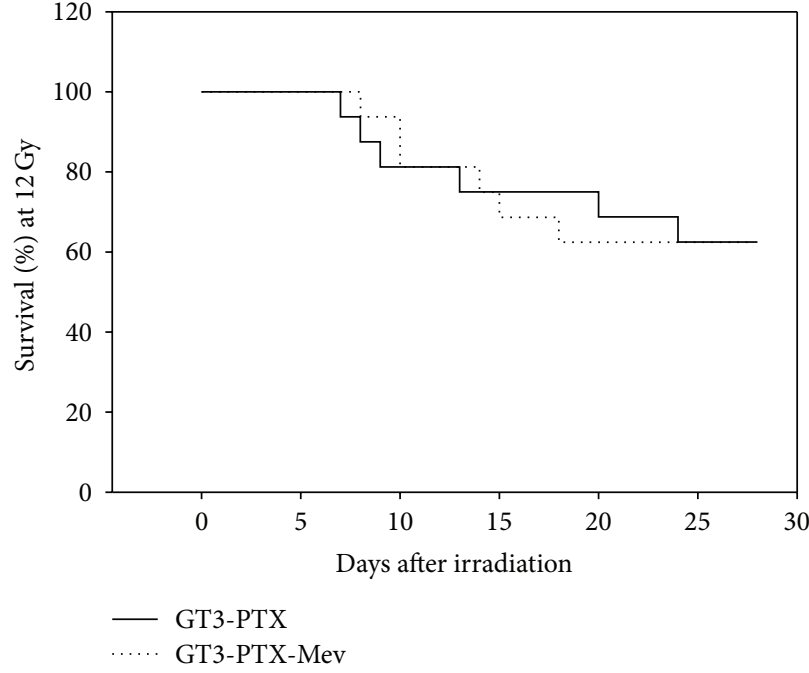

(a)

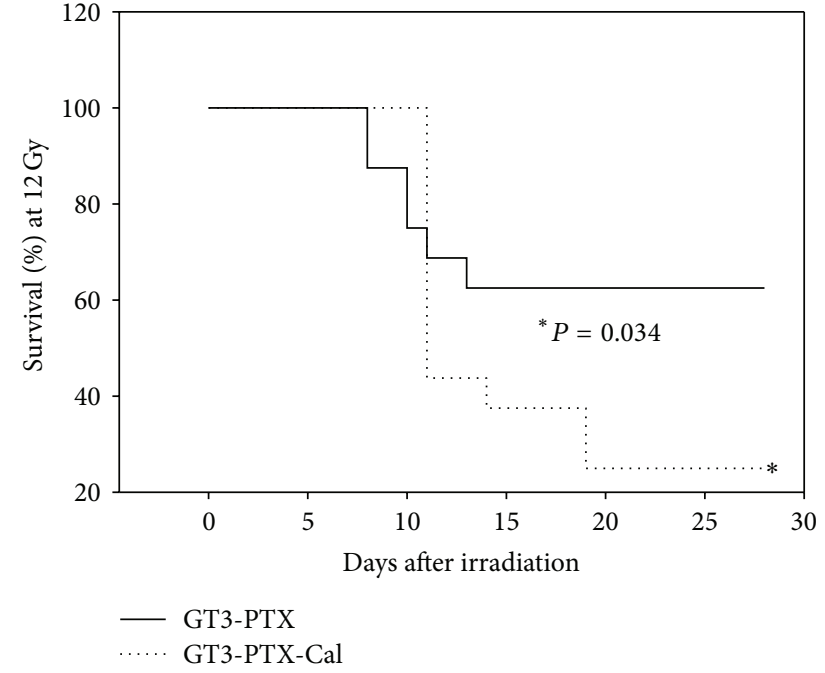

(b)

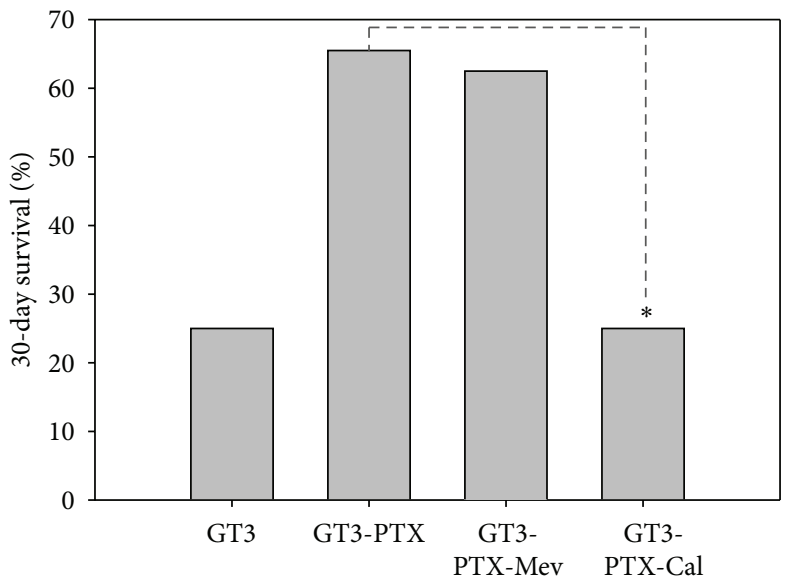

(c)

FIGURE 8: Effect of mevalonate and calmodulin on radioprotection by the GT3-PTX combination. Postirradiation survival study was conducted in mice $(n=16)$ treated with GT3, GT3-PTX, GT3-PTX-mevalonate, or GT3-PTX-calmodulin. (a) shows \% survival over 30 days in mice treated with $200 \mathrm{mg} / \mathrm{kg}$ of GT3 $(-24 \mathrm{~h}), 200 \mathrm{mg} / \mathrm{kg}$ of PTX $(-15 \mathrm{~min})$ with and without $30 \mathrm{mg} / \mathrm{kg}$ of mevalonate $(-24 \mathrm{~h})$. (b) shows \% survival over 30 days in mice treated with $200 \mathrm{mg} / \mathrm{kg}$ of GT3 $(-24 \mathrm{~h}), 200 \mathrm{mg} / \mathrm{kg}$ of PTX $(-15 \mathrm{~min})$ with and without $2000 \mu / \mathrm{kg}$ of calmodulin $(-15 \mathrm{~min})$. Calmodulin reduced the $\%$ survival $(P=0.034)$ when given in combination with GT3 and PTX. (c) shows the histogram of $\%$ survival in various treatment groups at the end of 30 days.

Clinical and animal studies show that injury from ionizing radiation is associated with loss of thrombomodulin from endothelium [41]. Also, PTX is shown to increase the levels of thrombomodulin in the endothelium by increasing cAMP $[40,42]$. It is conceivable that synergistic radioprotection by the GT3-PTX combination may involve beneficial effects on thrombomodulin levels.

\section{Conflict of Interests}

The authors report no conflict of interests. The authors have no direct financial relation with the commercial identities mentioned in the paper that might lead to a conflict of interests.

\section{Funding}

This work was supported by the U.S. Department of Defense Threat Reduction Agency Grant H.10027_07_AR_R (K. Sree Kumar), administered by The Henry M. Jackson Foundation for the Advancement of Military Medicine, Inc., and HDTRA 1-07-C-0028 (Martin Hauer-Jensen).

\section{Acknowledgments}

The authors would like to thank Lyudmila Romanyukha, Kevin Hieber, Kristen Gambles, and Stephanie McCormack for their help with the experiments. 


\section{References}

[1] C. N. Coleman, H. B. Stone, J. E. Moulder, and T. C. Pellmar, "Modulation of radiation injury," Science, vol. 304, no. 5671, pp. 693-694, 2004.

[2] F. Dumont, A. L. Roux, and P. Bischoff, "Radiation countermeasure agents: an update," Expert Opinion on Therapeutic Patents, vol. 20, no. 1, pp. 73-101, 2010.

[3] M. Mac Manus, K. Lamborn, W. Khan, A. Varghese, L. Graef, and S. Knox, "Radiotherapy-associated neutropenia and thrombocytopenia: analysis of risk factors and development of a predictive model," Blood, vol. 89, no. 7, pp. 2303-2310, 1997.

[4] J. E. Arrand and B. D. Michael, "Recent advances in the study of ionizing radiation damage and repair," International Journal of Radiation Biology, vol. 61, no. 6, pp. 717-720, 1992.

[5] G. Multhoff and J. Radons, "Radiation, inflammation, and immune responses in cancer," Frontiers in Oncology, vol. 2, p. 58, 2012.

[6] W. P. Roos and B. Kaina, "DNA damage-induced cell death by apoptosis," Trends in Molecular Medicine, vol. 12, no. 9, pp. 440450, 2006.

[7] B. M. Y. Cheung and C. Li, "Diabetes and hypertension: is there a common metabolic pathway?" Current Atherosclerosis Reports, vol. 14, no. 2, pp. 160-166, 2012.

[8] B. Garcia-Bailo, A. El-Sohemy, P. S. Haddad et al., "Vitamins $\mathrm{D}, \mathrm{C}$, and $\mathrm{E}$ in the prevention of type 2 diabetes mellitus: modulation of inflammation and oxidative stress," Biologics, vol. 5, pp. 7-19, 2011.

[9] S. Kulkarni, S. P. Ghosh, M. Hauer-Jensen, and K. S. Kumar, "Hematological targets of radiation damage," Current Drug Targets, vol. 11, no. 11, pp. 1375-1385, 2010.

[10] A. M. Farese, F. Herodin, J. P. McKearn, C. Baum, E. Burton, and T. J. MacVittie, "Acceleration of hematopoietic reconstitution with a synthetic cytokine (SC-55494) after radiation-induced bone marrow aplasia," Blood, vol. 87, no. 2, pp. 581-591, 1996.

[11] J. P. Williams, S. L. Brown, G. E. Georges et al., "Animal models for medical countermeasures to radiation exposure," Radiation Research, vol. 173, no. 4, pp. 557-578, 2010.

[12] S. P. Ghosh, S. Kulkarni, K. Hieber et al., "Gamma-tocotrienol, a tocol antioxidant as a potent radioprotector," International Journal of Radiation Biology, vol. 85, no. 7, pp. 598-606, 2009.

[13] S. Kulkarni, S. P. Ghosh, M. Satyamitra et al., "Gammatocotrienol protects hematopoietic stem and progenitor cells in mice after total-body irradiation," Radiation Research, vol. 173, no. 6, pp. 738-747, 2010.

[14] M. Berbe, Q. Fu, M. Boerma, J. Wang, K. S. Kumar, and M. Hauer-Jensen, " $\gamma$-Tocotrienol ameliorates intestinal radiation injury and reduces vascular oxidative stress after total-body irradiation by an HMG-CoA Reductase-dependent mechanism," Radiation Research, vol. 171, no. 5, pp. 596-605, 2009.

[15] S. S. Kulkarni, L. H. Cary, K. Gambles, M. Hauer-Jensen, K. S. Kumar, and S. P. Ghosh, "Gamma-tocotrienol, a radiation prophylaxis agent, induces high levels of granulocyte colonystimulating factor," International Immunopharmacology, vol. 14, no. 4, pp. 495-503, 2012.

[16] E. Ernst, "Pentoxifylline for intermittent claudication. A critical review," Angiology, vol. 45, no. 5, pp. 339-345, 1994.

[17] H. R. Dettelbach and D. M. Aviado, "Clinical pharmacology of pentoxifylline with special reference to its hemorrheologic effect for the treatment of intermittent claudication," Journal of Clinical Pharmacology, vol. 25, no. 1, pp. 8-26, 1985.
[18] P. Haddad, B. Kalaghchi, and F. Amouzegar-Hashemi, "Pentoxifylline and vitamin E combination for superficial radiationinduced fibrosis: a phase II clinical trial," Radiotherapy and Oncology, vol. 77, no. 3, pp. 324-326, 2005.

[19] M. Amano, H. Monzen, M. Suzuki et al., "Increase in tumor oxygenation and potentiation of radiation effects using pentoxifylline, vinpocetine and ticlopidine hydrochloride," Journal of Radiation Research, vol. 46, no. 4, pp. 373-378, 2005.

[20] M. W. Dion, D. H. Hussey, and J. W. Osborne, "The effect of pentoxifylline on early and late radiation injury following fractionated irradiation in $\mathrm{C} 3 \mathrm{H}$ mice," International Journal of Radiation Oncology Biology Physics, vol. 17, no. 1, pp. 101-107, 1989.

[21] C. E. Rübe, F. Wilfert, D. Uthe et al., "Modulation of radiationinduced tumour necrosis factor $\alpha$ (TNF- $\alpha$ ) expression in the lung tissue by pentoxifylline," Radiotherapy and Oncology, vol. 64 , no. 2, pp. 177-187, 2002.

[22] M. Berbée, Q. Fu, S. Garg, S. Kulkarni, K. S. Kumar, and M. Hauer-Jensen, "Pentoxifylline enhances the radioprotective properties of $\gamma$-Tocotrienol: differential effects on the hematopoietic, gastrointestinal and vascular systems," Radiation Research, vol. 175, no. 3, pp. 297-306, 2011.

[23] N. Y. Kim, H. O. Pae, Y. C. Kim et al., "Pentoxifylline potentiates nitric oxide production in interleukin- $\beta$-stimulated vascular smooth muscle cells through cyclic AMP-dependent protein kinase A pathway," General Pharmacology, vol. 35, no. 4, pp. 205-211, 2000.

[24] D. E. Cox and R. D. Edstrom, "Inhibition by calmodulin of the cAMP-dependent protein kinase activation of phosphorylase kinase," Journal of Biological Chemistry, vol. 257, no. 21, pp. 12728-12733, 1982.

[25] S. Ishikawa, T. Saito, and T. Kuzuya, "Evidence for a role of calmodulin in cellular cAMP production in response to vasopressin, prostaglandin E2 and forskolin in cultured rat renal papillary collecting tubule cells," Nippon Naibunpi Gakkai zasshi, vol. 61, no. 8, pp. 823-834, 1985.

[26] D. J. Honess, I. F. Dennis, and N. M. Bleehen, "Pentoxifylline: its pharmacokinetics and ability to improve tumour perfusion and radiosensitivity in mice," Radiotherapy and Oncology, vol. 28, no. 3, pp. 208-218, 1993.

[27] S. I. Krivenko, S. I. Dryk, M. E. Komarovskaya, and L. V. Karkanitsa, "Ionizing radiation increases TNF/cachectin production by human peripheral blood mononuclear cells in vitro," International Journal of Hematology, vol. 55, no. 2, pp. 127-130, 1992.

[28] J. S. Nandi, K. G. Nair, and S. Deo, "Inhibition cAMP-phosphodiesterase in the rat heart by pentoxifylline-a new xanthine derivative," Advances in Myocardiology, vol. 1, pp. 359-365, 1980.

[29] W. Y. Cheung, T. J. Lynch, R. W. Wallace, and E. A. Tallant, "cAMP renders Ca2+-dependent phosphodiesterase refractory to inhibition by a calmodulin-binding protein (calcineurin)," Journal of Biological Chemistry, vol. 256, no. 9, pp. 4439-4443, 1981.

[30] C. Nieder, F. B. Zimmermann, M. Adam, and M. Molls, "The role of pentoxifylline as a modifier of radiation therapy," Cancer Treatment Reviews, vol. 31, no. 6, pp. 448-455, 2005.

[31] A. Ward and S. P. Clissold, "Pentoxifylline: a review of its pharmacodynamic and pharmacokinetic properties, and its therapeutic efficacy," Drugs, vol. 34, no. 1, pp. 50-97, 1987.

[32] D. C. Dale, "Colony-stimulating factors for the management of neutropenia in cancer patients," Drugs, vol. 62, supplement 1, pp. 1-15, 2002. 
[33] T. J. MacVittie, A. M. Farese, W. G. Smith, C. M. Baum, E. Burton, and J. P. McKearn, "Myelopoietin, an engineered chimeric IL-3 and G-CSF receptor agonist, stimulates multilineage hematopoietic recovery in a nonhuman primate model of radiation-induced myelosuppression," Blood, vol. 95, no. 3, pp. 837-845, 2000.

[34] S. Kulkarni, P. K. Singh, S. P. Ghosh, A. Posarac, and V. K. Singh, "Granulocyte colony-stimulating factor antibody abrogates radioprotective efficacy of gamma-tocotrienol, a promising radiation countermeasure," Cytokine, vol. 62, no. 2, pp. 278285, 2013.

[35] R. Ansari, M. W. Gaber, B. Wang, C. B. Pattillo, C. Miyamoto, and M. F. Kiani, "Anti-TNFA (TNF- $\alpha$ ) treatment abrogates radiation-induced changes in vascular density and tissue oxygenation," Radiation Research, vol. 167, no. 1, pp. 80-86, 2007.

[36] J. T. Chao, A. Gapor, and A. Theriault, "Inhibitory effect of $\delta$ tocotrienol, a HMG CoA reductase inhibitor, on monocyteendothelial cell adhesion," Journal of Nutritional Science and Vitaminology, vol. 48, no. 5, pp. 332-337, 2002.

[37] V. B. Wali, S. V. Bachawal, and P. W. Sylvester, "Suppression in mevalonate synthesis mediates antitumor effects of combined statin and $\gamma$-tocotrienol treatment," Lipids, vol. 44, no. 10, pp. 925-934, 2009.

[38] D. E. Cox, M. H. Meinke, and R. D. Edstrom, "Mechanism of calmodulin inhibition of cAMP-dependent protein kinase activation of phosphorylation kinase," Archives of Biochemistry and Biophysics, vol. 259, no. 2, pp. 350-362, 1987.

[39] P. Mercié, M. Seigneur, and C. Conri, "Plasma thrombomodulin as a marker of vascular damage in systemic sclerosis," Journal of Rheumatology, vol. 22, no. 7, pp. 1440-1441, 1995.

[40] M. Seigneur, P. Dufourcq, F. Belloc, M. Lenoble, M. Renard, and M. R. Boisseau, "Influence of pentoxifylline on membrane thrombomodulin levels in endothelial cells submitted to hypoxic conditions," Journal of Cardiovascular Pharmacology, vol. 25, supplement 2, pp. S85-S87, 1995.

[41] C. C. Ross, S. L. MacLeod, J. R. Plaxco et al., "Inactivation of thrombomodulin by ionizing radiation in a cell-free system: possible implications for radiation responses in vascular endothelium," Radiation Research, vol. 169, no. 4, pp. 408-416, 2008.

[42] S. Ohdama, S. Takano, K. Ohashi, S. Miyake, and N. Aoki, "Pentoxifylline prevents tumor necrosis factor-induced suppression of endothelial cell surface thrombomodulin," Thrombosis Research, vol. 62, no. 6, pp. 745-755, 1991. 


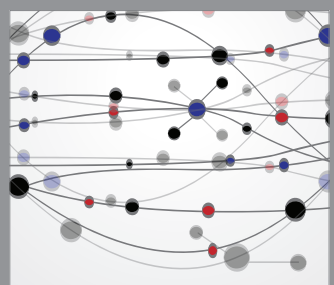

The Scientific World Journal
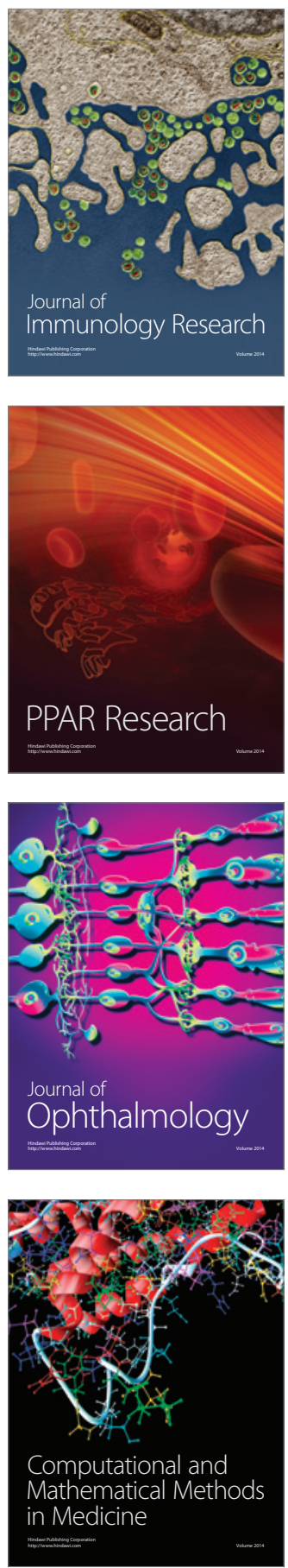

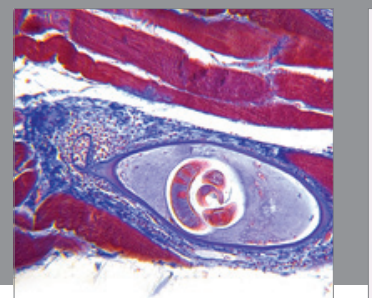

Gastroenterology

Research and Practice
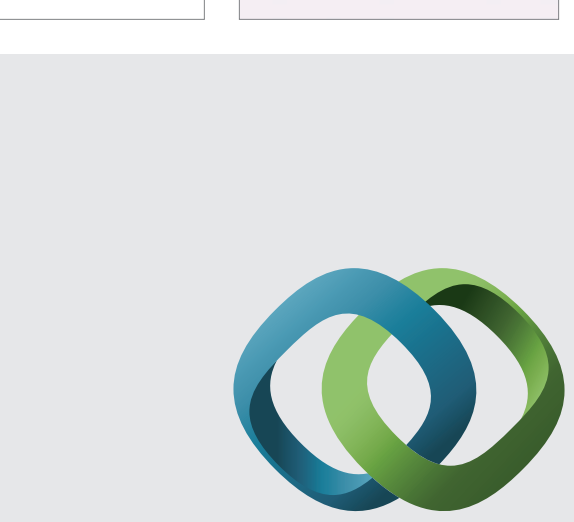

\section{Hindawi}

Submit your manuscripts at

http://www.hindawi.com
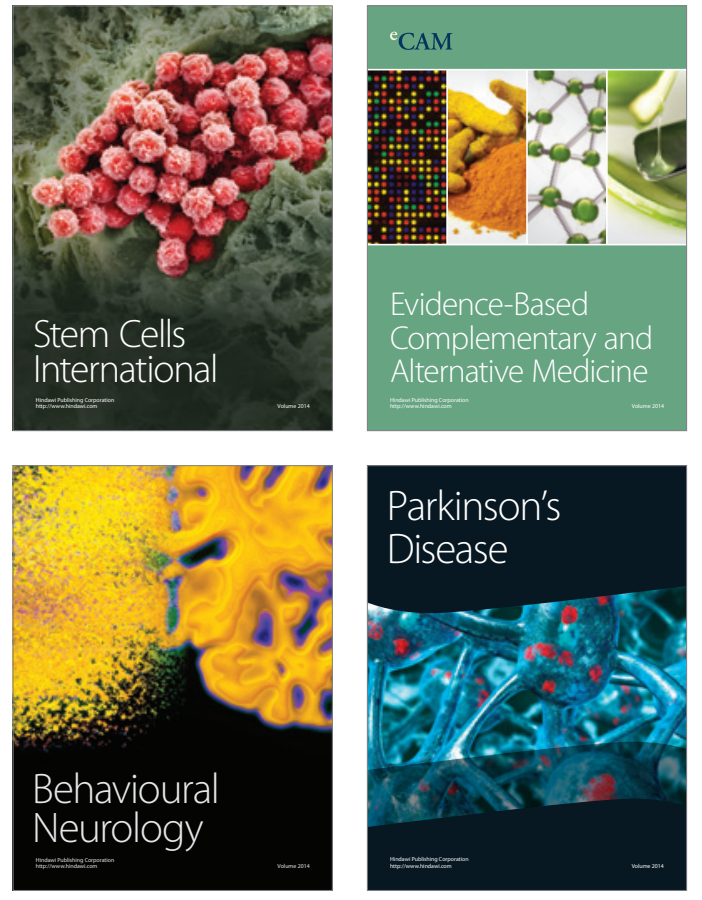
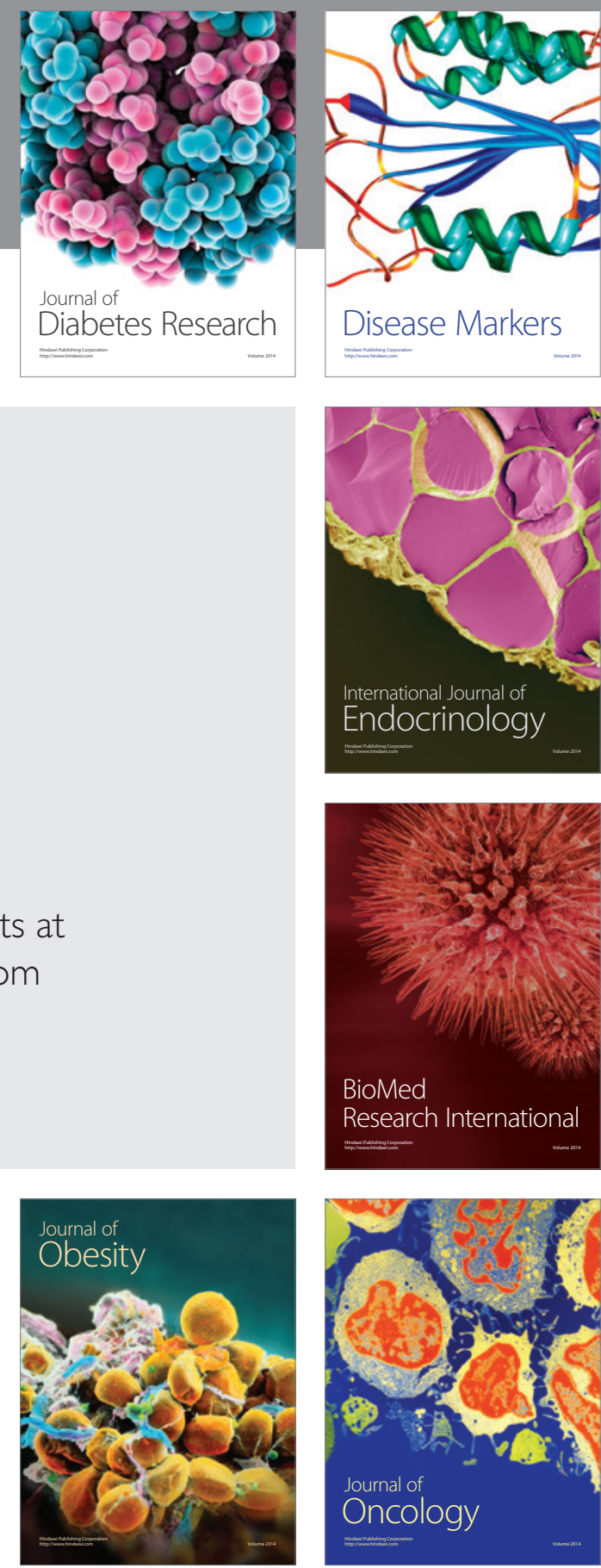

Disease Markers
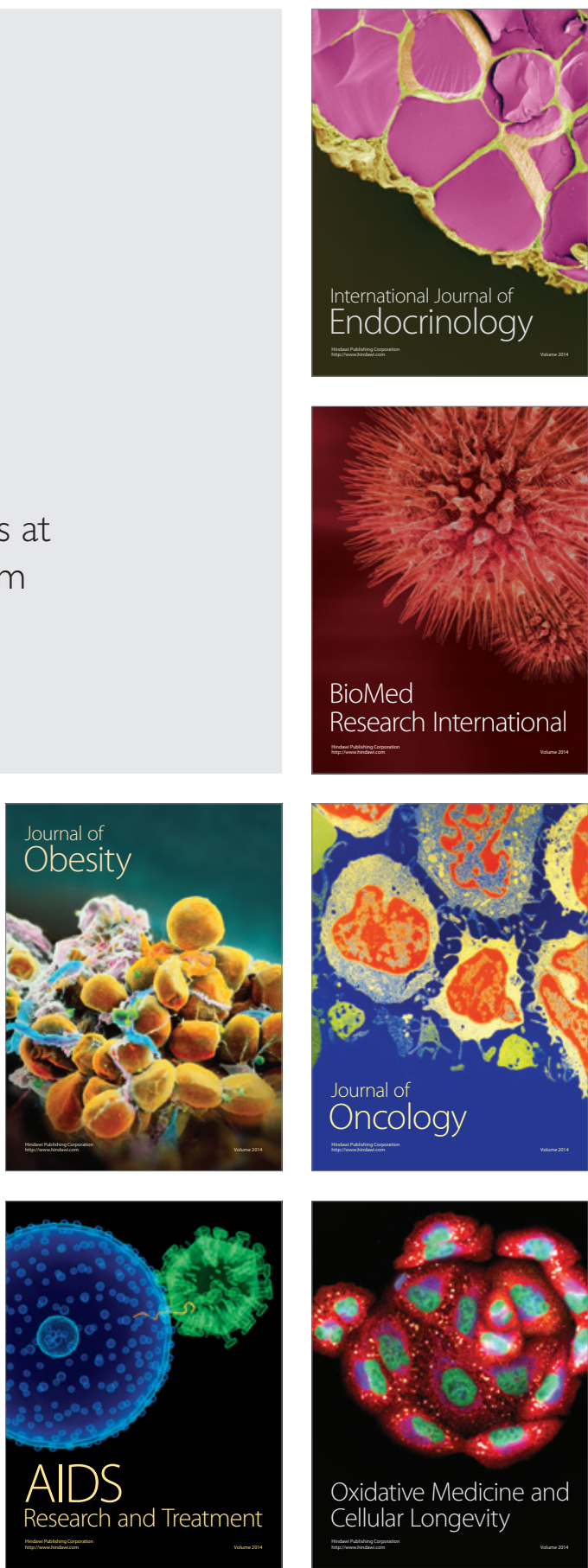